\title{
Evaluation of synchrony of feeding behaviour in individual Acartia hudsonica (Copepoda, Calanoida)
}

\author{
Valeriano Rodriguez ${ }^{1}$, Edward G. Durbin ${ }^{2}$ \\ ${ }^{1}$ University of Málaga, Departament of Ecology, Campus Univesitario de Teatinos, E-29071 Málaga, Spain \\ ${ }^{2}$ University of Rhode Island, Graduate School of Oceanography, South Ferry Road, Narragansett, Rhode Island 02882, USA
}

\begin{abstract}
Variability in individual feeding behaviour of Acartia hudsonica was studied in 34 samples, each of 100 individuals. The samples were collected during 3 day-night cycles from a large experimental seawater system in Norfolk, Virginia, USA. Fluorometric measurements were made to determine gut pigment contents and evacuation rates, from which ingestion rates and daily rations were calculated. Results show that gut contents were almost always $<1.2 \mathrm{ng}$ pigment copepod ${ }^{-1}$. Coefficients of variation (CV) calculated for each sample, which were used as indices of synchrony, were always $<70 \%$. The highest frequency of synchronized behaviour was observed, independent of time, in individuals from bottom samples. At night, the probability of obtaining any particular $\mathrm{CV}$ in individuals from bottom or surface was the same. About $45 \%$ of individuals displayed moderately high contents $(0.2$ to $0.5 \mathrm{ng})$ both day and night, but the percentage of copopods with $>0.5 \mathrm{ng}$ pigment increased from $16 \%$ in the day-time to $42 \%$ at night. This non-uniform pattern of gut contents suggests the copepods were feeding in short-term episodes which were perhaps more frequent at night. Since food was in excess at all times at all depths, and experimental temperatures did not vary, light was probably the principal factor controlling the observed feeding periodicity.
\end{abstract}

\section{INTRODUCTION}

Studies of feeding behaviour of any animal species above a certain body size are usually conducted on individual animals. However, for relatively small animals such as copepods, it is usual to work with groups of individuals. This is because it is difficult and time-consuming to make precise measurements on very small individuals. Measurements made on groups of animals are never entirely satisfactory, however, because they tend to mask a number of important features of feeding behaviour such as the deviation of individual values from the mean.

The recent proliferation of in situ studies of plankton feeding behaviour with different spatial and temporal scales, but especially those within a 24 h cycle (Baars \& Oosterhuis 1984, Pagano \& Saint-Jean 1985, Bautista et al. 1988, Durbin et al. 1990, Morales et al. 1990, Peterson et al. 1990, Rodriguez et al. 1991), was stimulated by the application of a fluorescence method (Mackas \& Bohrer
1976) for measuring gut contents. There are methodological assumptions that have to be made and there are several potential sources of error such as pigment assimilation in the digestion process and evacuation in starving copepods, that have been widely discussed (Madin \& Cetta 1984, Conover et al. 1986, Lorenzen \& Downs 1986, Wang \& Conover 1986, Dagg \& Walser 1987), but the rapidity of this method allows a large number of replicates of gut contents of individual copepods in each sample to be made and compared. Several studies have used this approach and have demonstrated the existence of individual variability (Mackas \& Burns 1986, Moebly 1987, Kleppel et al. 1988, Durbin et al. 1990). The objective of our present study was to analyse the in situ feeding behaviour of individuals of Acartia hudsonica and to explore the degree of possible synchrony or variance of these activities on a day/night scale at times of food excess, to determine how much individual variability contributes to the observed population pattern. 


\section{MATERIAL AND METHODS}

All samples were collected from a single $120 \mathrm{~m}$ long phytoplankton-zooplankton patch over a $3 \mathrm{~d}$ period (April 4, $5 \& 6,1987$ ). This $2000 \mathrm{~m}^{3}$ patch was contained in a $120 \mathrm{~m}$ long center section of the $675 \mathrm{~m}$ long, $7.8 \mathrm{~m}$ wide, $3.4 \mathrm{~m}$ deep Langley tow tank at NASA Langley Research Center, Hampton, Virginia, USA (Donaghay 1988j. The patch had been initiated $2 \mathrm{wk}$ prior to sampling by filling the bag with a mixture of natural plankton and $3 \mu \mathrm{m}$ filtered seawater. Light was provided with $1000 \mathrm{~W}$ metal halide lamps operated on a $16: 8 \mathrm{~h}$ (L:D) photoperiod. These lights provided $100 \mu$ Einstein at the surface with an average light intensity of $33 \mu$ Einstein. The patch was enriched by adding $N, P$, Si to maintain concentrations above $2 \mu \mathrm{M}$ $\mathrm{N}$ and $\mathrm{Si}$ and $0.2 \mathrm{mM}$ P. The patch was mixed by an automated stirrer. There were 3 sampling stations along the innermost stretch of the channel at which bottom and surface samples were taken twice a day with a submerged pump. Sampling of water during the day and night experimental periods took place between 08:30 and 10:00 h, and between 16:00 and 18:00 h local time. Each sample consisted of between 70 and $100 \mathrm{l}$ of seawater. This was filtered by a $100 \mu \mathrm{m}$ sieve to capture the adult copepods; these were then immediately frozen in liquid nitrogen before being transferred to the laboratory of the Graduate School of Oceanography (Rhode Island). Pigment concentration [Chlorophyll a (chl a) + phaeopigments] measurements in seawater were made on 4 replicates of $10 \mathrm{ml}$ surface and bottom samples taken at each sampling time at Stn 3 only.

To calculate evacuation rate constants, copepods were obtained from short horizontal trawls along the length of the patch during the night period. The material retained in the cod-end was washed gently several times with filtered seawater and immediately transferred to an incubation vessel containing filtered seawater. A series of samples were then removed from the vessel at intervals of $3,6,9,12,15,18,30,45$ and 95 min from the start of the experiment and each sample was immediately frozen and stored in liquid nitrogen for transfer to the laboratory.

In the laboratory, 100 adult females of Acartia hudsonica were picked out from each sample under cold and low light conditions, rinsed briefly with filtered water, and placed individually in tubes containing $4 \mathrm{ml}$ of acetone. These were then left overnight in dark, cold conditions to extract. The gut contents of specimens for the evacuation-rate experiments were measured collectively in groups of 25 rather than individually, but they were processed in the same way as the other materials. Measurements were made of 4 replicates of the samples from each incubation interval, except those taken at $45 \mathrm{~min}$ ( 3 replicates) and $95 \mathrm{~min}$ (2 replicates). The fluorescence of the extracts was measured with a Turner Designs Model 10 Fluorometer, before and after acidification. The experimental values were corrected by subtracting the mean value of 35 acetone blanks. Pigment content is expressed as chl $a+$ phaeopigment; the calculations were based on the equations of Lorenzen (1966), as modified for use at the Marine Ecosystem Research Laboratory (Lambert \& Oviatt 1986).

The size structure of the Acartia hudsonica adult females was determined from measurements of 300 randomly selected specimens from a mix of female specimens from all the samples. We measured cephalothorax width and total body length (from the top of the head to the base of the caudal rami) of each specimen in the group using an AMS (VIDS IV) semiautomatic image analyser that receives the image from an inverted microscope fitted with a television camera.

\section{RESULTS AND DISCUSSION}

\section{Size structure}

The total body length of the population of Acartia hudsonica adult females showed a normal size distribution with a mean value of $1052 \mu \mathrm{m}$, and coefficient of variation $(\mathrm{CV})=7.52 \%$. Values ranged from 850 to $1308 \mu \mathrm{m}$.

\section{Environmental conditions}

Throughout the experimental period, the thermal and trophic conditions of the seawater were very homogeneous along the length of the patch. Water temperature was $10 \pm 0.2^{\circ} \mathrm{C}$ and the phytoplankton biomass, expressed in term of fluorescent pigment concentration was always very high (range 32.10 to $42.73 \mu \mathrm{g} \mathrm{l}^{-1}$, mean: $39.41 \pm 3.20 \mu \mathrm{gl}^{-1}, \mathrm{n}=48$ ). The predominant pigment was active chl $a$ and the phaeopigments represented between 11.56 and $33.25 \%$ of the total: the mean value was $20.37 \pm 6.38 \%(n=48)$ Diatoms dominated the phytoplankton community (Donaghay 1988).

\section{Variability in individual gut contents}

The mean value of individual gut pigment content of 3406 of the specimens processed was $0.39 \mathrm{ng}(\mathrm{CV}=$ $58.46 \%$ ); the maximum value was $1.56 \mathrm{ng}$ Most of the frequency distributions of individual gut contents appeared to be log-normal (Fig. 1). 


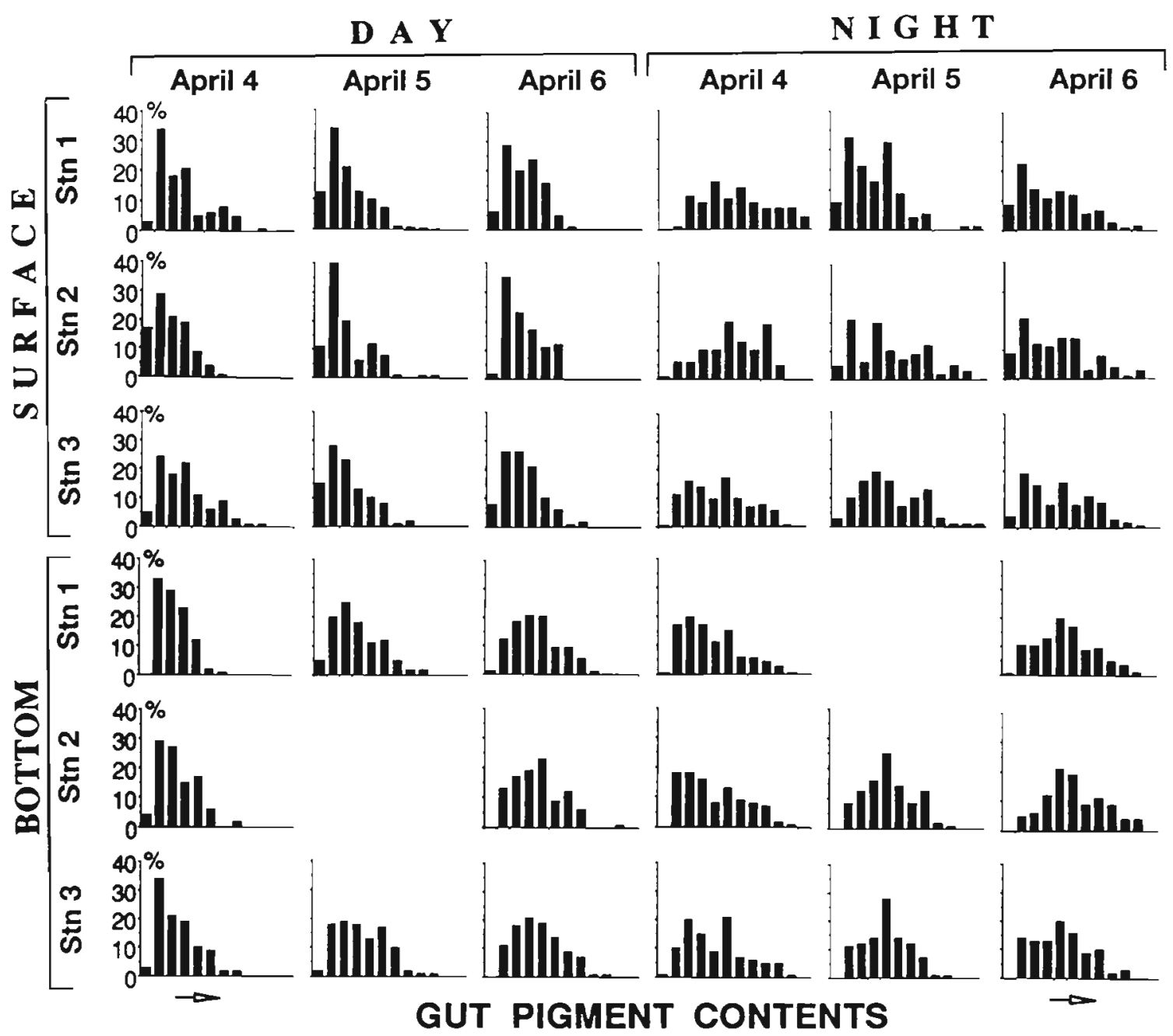

Fig. 1. Acartia hudsonica. Frequericy distribution of individual gut pigment contents for each of the 34 samples analysed 1100 females per sample) arranged to present 2 contrasts: light-dark (day-time, night-time) in columns and depth of capture (surface, bottom) in rows. The 3 successive days of sampling are shown in the subcolumns, and the 3 sample stations in the subrows. Class interval $=0.1 \mathrm{ng}$ pigment. The first and last classes shown are $0.00-0.10$ and $1.10-1.20 \mathrm{ng}$ pigment

Previous studies (Mackas \& Burns 1986, Kleppel et al. 1988 ) report the order of individual variability of gut pigments as 10 -fold and warn that with this level of variability any estimates of individual levels based on the mean, made on large numbers of animals, should be interpreted with extreme caution. In the present case, the range of values within each sample always was $0.6 \mathrm{ng}$, and in $53 \%$ of the samples the range was $1 \mathrm{ng}$.

In each sample individual synchrony or population variability in feeding behaviour was estimated as the coefficient of variation, i.e. the degree of dispersion of the individual gut pigment contents around the mean. Because it is expressed as the percentage of the mean, it is independent of the absolute value of the mean. Fig. 2 displays the frequency distribution of the $\mathrm{CV}$ in $5 \%$ class intervals for the total sample set (Fig. 2A), for the sample subgroups that represent the day and night samples (Fig. 2B), and for the bottom and surface samples (Fig. 2C). The complete set of coefficients show a bimodal distribution in which the first peak ( $29 \%$ of the samples) represents the CV values between 45 and $50 \%$ and the second peak $(19.36 \%$ of the samples) the values between 60 and $65 \%$. With the exception of bottom samples, a similar bimodal pattern was seen in each of the sample subgroups mentioned above, with the following differences. In the day samples, the basic bimodal pattern was intensified because the frequencies of the modal classes increased while those of the extreme classes decreased. On the other hand, in the nocturnal samples there was an increase in the relative importance of samples that displayed a more uniform individual behaviour (decrease of the CV values) and also of other samples which displayed more variance. There are interesting contrasts between samples of bottom and surface waters because in the bottom samples of both day and night 

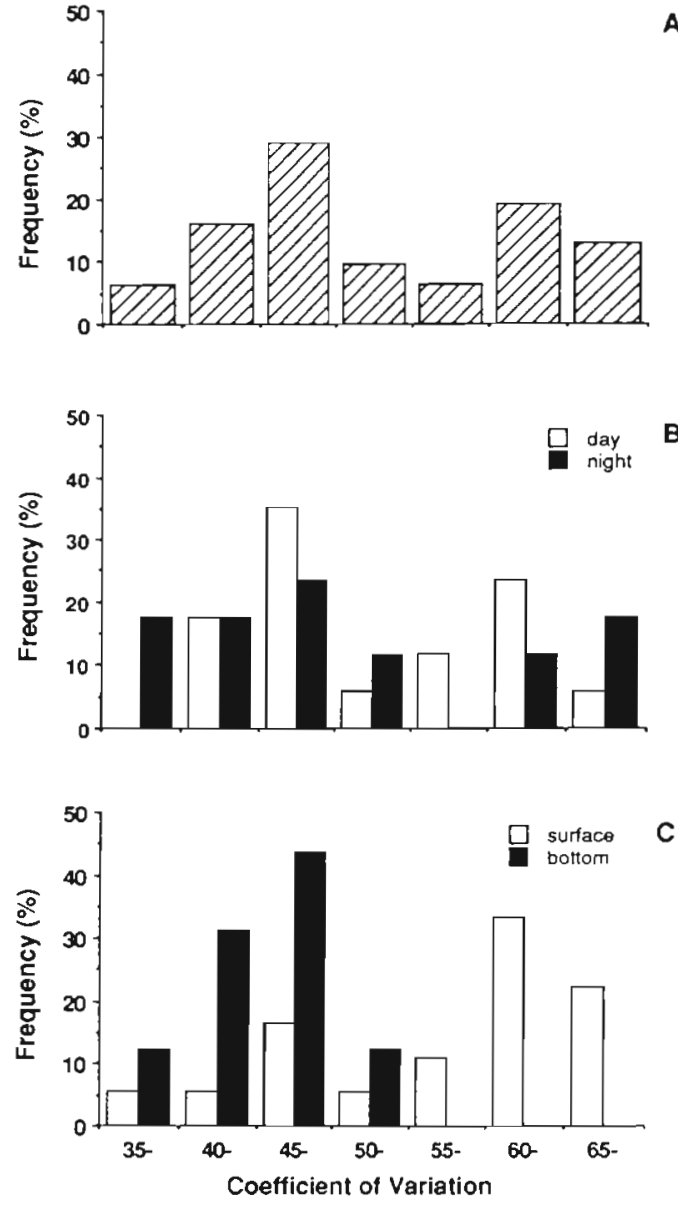

Fig. 2. Acartia hudsonica. Frequency distribution of the coefficients of variation: (A) all samples $(n=34)$; $(B)$ day-time and night-time samples $(n=17) ;(C)$ surface $(n=18)$ and bottom samples $(n=16)$

the second peak (larger values of variability) has disappeared, while at the surface it is intensified, perhaps in relationship with the observation (Head 1992) that light may have actually had a direct effect on the degree of pigment destruction occurring in copepod guts. In every case, the CV values were less than $70 \%$. This figure is less than that reported by Kleppel et al. (1988) for Acartia tonsa, where values $>100 \%$ were normally found, but declining to $\leq 70 \%$ during evening and morning twilight ( $1 \mathrm{~h}$ before sunset and $1 \mathrm{~h}$ after sunrise)

\section{Daily feeding cycles}

Individual variance found in the copepods in this work appears compatible with changes in the feeding behaviour of the population. Many studies of shortterm variation of copepod feeding behaviour have shown diel periodicities, even when the distribution of food in the water column is homogeneous (Mayzaud et al. 1984, Daro 1985, Durbin et al. 1990). Patterns cân vary however; some have just one nocturnal peak, while others display peaks at both dusk and dawn (Dagg \& Grill 1980, Simard et al. 1983, Pagano \& SaintJean 1985, Stearns 1986, Head \& Harris 1987, Bautista et al. 1988, Morales et al. 1990). The observed variation in the amount of gut contents throughout the day has been variously attributed by different authors to either continuous feeding of copepods which are vertically migrating in a water mass with irregular concentrations of food (Hart 1977, Boyd et al. 1980, Dagg \& Grill 1980, Simard et al. 1983); or to diel variations in feeding activity (Mackas \& Bohrer 1976, Pagano \& SaintJean 1985, Bautista et al. 1988, Durbin et al. 1990). Furhermore, the day and night feeding behaviour of a given species of copepod may vary with season (Baars \& Oosterhuis 1984). This observed 'plasticity' of feeding behaviour led to suggestions that physical and biological factors such as light and temperature, and food and predation could influence the diel grazing of copepods (Roman et al. 1988).

All the above in situ studies use the mean gut contents of several groups of copepods as the parameter to express feeding behaviour patterns. The supposition is that all the copepods in the group behave similarly, but this is not necessarily the case. For example, if the means of gut contents do not vary during a $24 \mathrm{~h}$ cycle it suggests that the individuals of the group are feeding continuously. The same pattern would occur, however, if the population of copepods is feeding intermittently and at random throughout the day. Intermittent feeding and the observation of a discontinuous pattern implies that the feeding behaviour of the copepods is similar, i.e. that there is synchronicity in the episodic feeding (Head \& Harris 1987, Kleppel et al. 1988).

We used 2-way variance analysis to carry out a statistical analysis of the differences in the feeding behaviours of Acartia hudsonica on an individual basis according to either time of day (1st Factor: day-timenight-time) or the depth level occupied (2nd Factor: surface-bottom). The number of replicates was equal to the total number of individual measurements made for each of the 4 possible combinations of the 2 factors, independent of the station at which the samples were taken or the date of sampling.

Regrouping the data in this way (Fig. 3) showed that although Acartia hudsonica is probably a nocturnal feeder, like all the genus Acartia (Stearns 1986, Bautista et al. 1988, Kleppel et al. 1988), in this study it was feeding during the day as well as at night.

Our use of the gut-pigment-content categories employed by Kleppel et al. (1988) (low: <0.2 ng, moderate: 0.2 to $0.5 \mathrm{ng}$, high: $>0.5 \mathrm{ng}$ ), showed that in day-time, $52 \%$ of the individuals had moderate levels 


\section{SURFACE BOTTOM}
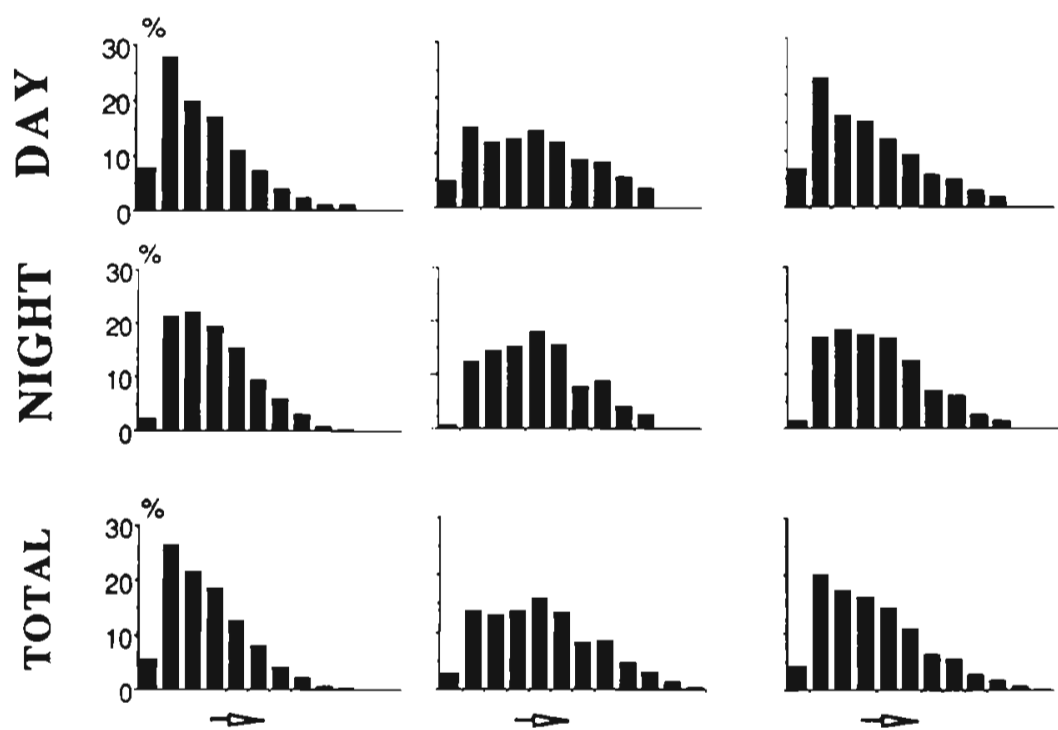

GUT PIGMENT CONTENTS

Fig. 3. Acartia hudsonica. Frequency distribution of the amounts of individual gut-pigment contents in day-time and night-time samples from surface and bottom water

of pigments, $32 \%$ had low levels, and only $16 \%$ had high levels. The respective night-time values were 42 , 16 and $42 \%$. Consequently, it appears that a relatively high percentage $(42 \%$ in this case) of copepods with high levels of gut pigment contents may be characteristic of nocturnal samples because it contrasts clearly with the lower percentage (16\% in this work) of copepods with high levels of gut pigment contents from day-time samples. This approximately 3 -fold increase appears to have been produced by a decrease of some $50 \%$ in those individuals with low levels of gut pigment contents at night in comparison with the daytime samples. On the other hand, for Arcatia tonsa (Kleppel et al. 1988), the differences between day and night are reported to affect mainly the relative importance of those copepods with moderate gut pigment contents, namely $17 \%$ of day-time and $55 \%$ of nighttime specimens, while the percentage of copepods with high levels of gut pigment contents remained constant, between 8 to $10 \%$, both day and night.

The results of the variance analysis (Table 1 ) show a very significant difference $(p \ll 0.001)$ between the day-time and night-time gut contents, and also between individuals taken from the surface and bottom. The interaction is also significant. The observed differences between day and night coincide with other observations of daily feeding cycles of the Acartia genus (Pagano \& Saint-Jean 1985, Bautista et al. 1988). The fact that the observations were of copepods that had spent their total life-cycle in a medium with a superabundance of food distributed homogeneously means that we can discount the influence of any prior conditioning of feeding habits on the diel pattern observed in this present work. The main divergence between conditions was light intensity and this may have been the controlling factor of the observed difference in $A$. hudsonica feeding activity (Head et al. 1985, Stearns 1986).

\section{Feeding rates}

The ingestion rate was calculated as the product of gut contents (ng of pigment copepod ${ }^{-1}$ ) and the evacuation rate constant $\left(\mathrm{h}^{-1}\right)$ assuming the gut contents represent the amount of phytoplankton ingested during a period of time equal to a constant gutpassage time. The key factor in these determinations is the evacuation rate constant (Kiørboe et al. 1985, Kiørboe \& Tiselius 1987) because its value appears to depend on temperature (Dagg \& Grill 1980, Kiørboe et al. 1982, Dagg \& Wyman 1983, Dam \& Peterson 1988), or on the initial gut content (Baars \& Oosterhuis 1984, Baars \& Helling 1985, Dagg \& Walser 1987).

The decrease in gut pigment contents that occurred after placing the copepods in filtered seawater is shown in Fig. 4A and is best fitted by a negative exponential madel in which the slope of the curve represents the evacuation- or gut clearance-rate constant. However, some authors (Penry \& Jumars 1986, Penry \& Frost 1990) mention that an exponentional-decay

Table 1 ANOVA of the data in Fig. 3 to determine the influence of time of day and depth on individual gut-pigment contents of Acartia hudsonica

\begin{tabular}{|lrrrr|}
\hline $\begin{array}{l}\text { Source of } \\
\text { variation }\end{array}$ & $\begin{array}{c}\text { Sum of } \\
\text { squares }\end{array}$ & df & $\begin{array}{r}\text { Mean } \\
\text { square }\end{array}$ & $F$ \\
\hline Main effects & 20.829 & 2 & 10.414 & 227.576 \\
$\quad$ Time of day & 20.010 & 1 & 20.010 & 437.250 \\
$\quad$ Depth & 0.822 & 1 & 0.822 & 17.923 \\
2-way interactions & 1.238 & 1 & 1.238 & 27.042 \\
$\quad$ Time of day $\times$ Depth & 1.238 & 1 & 1.238 & 27.042 \\
Explained & 22.066 & 3 & 7.355 & 160.731 \\
Residual & 155.272 & 3393 & 0.046 & \\
Total & 177.339 & 3396 & 0.052 & \\
\hline
\end{tabular}



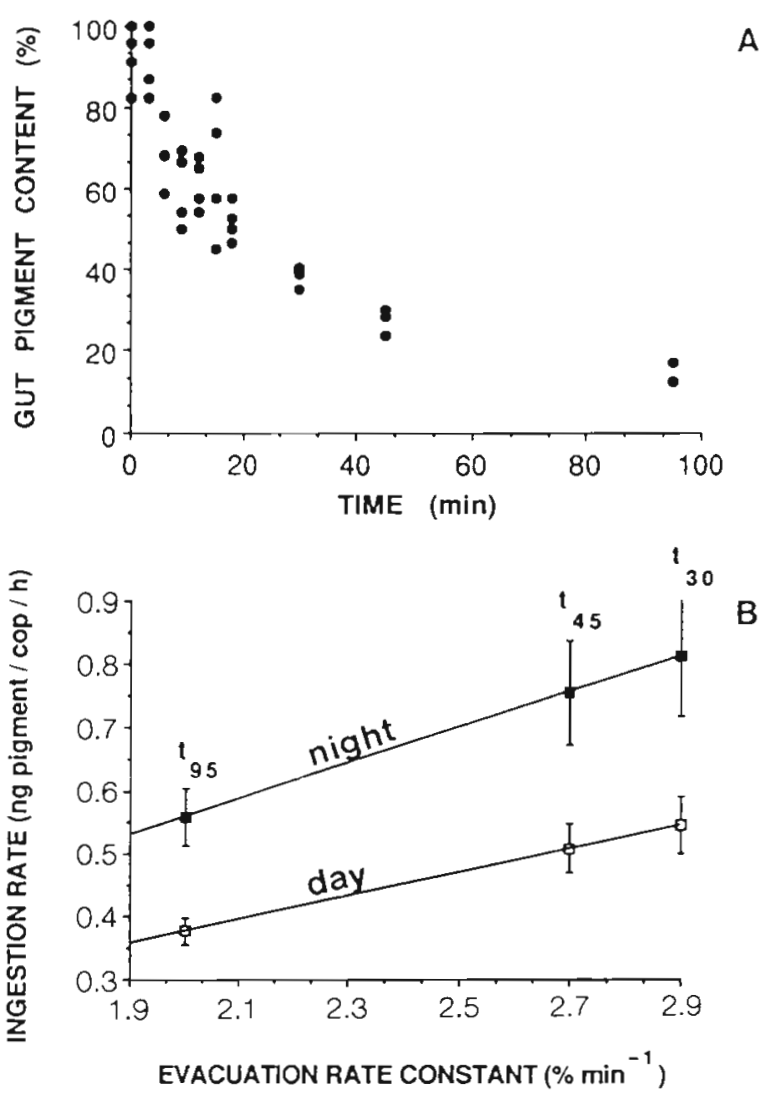

Fig. 4. Acartia hudsonica. (A) Time-dependent changes in gut-pigment contents (percentage of initial ng pigment) measured in the gut clearance experiment. (B) Changes in ingestion rate calculated from the evacuation rate constants of a series of 3 progressively longer starvation times $(t=30$, $45,95 \mathrm{~min}$ )

process may not be the best model of egestion. In the present study, the value of the slope of the chosen exponential process decreased as starvation time increased. Values calculated after 30,45 , and $95 \mathrm{~min}$ were $2.9,2.7$, and $2.0 \% \mathrm{~min}^{-1}$ respectively. The percentages of the initial gut contents that persisted at the end of these 3 incubation times fell within the ranges 30 to $40 \%, 20$ to $30 \%$, and 10 to $20 \%$, respectively. The average gut passage time, calculated as the reciprocals of the evacuation rate constants, were 40 min. This assumed equilibrium may well hold true for longterm feeding periods, but not for short ones, especially if the copepods are feeding intermittently or intensely for only a few hours by day.

The ingestion rates for all the determinations of individuals from the day-time and night-time samples were calculated separately using the evacuation rate constants discussed above. The mean values are shown in Fig. 4B. The day-night differences in gut contents revealed that the nocturnal ingestion rate was on average $(n=1700) 133 \%$ of the daytime rate: this is much less than the 260 to $300 \%$ difference reported by Durbin et al. (1990). The values calculated for day-time and night-time were, respectively, 0.51 and $0.76 \mathrm{ng}$ copepod $^{-1} \mathrm{~h}^{-1}$ using the evacuation rate of $2.7 \% \mathrm{~min}^{-1}$ obtained with 45 min of incubation. We extrapolated day and night grazing rates during the light and dark periods to calculate the total daily consumption of phytoplankton. The amount of food ingested throughout the whole day, calculated for a $16: 8 \mathrm{~h}$ (L:D) rhythm was $14.24 \mathrm{ng}$ pigment copepod ${ }^{-1} \mathrm{~d}^{-1}$. If we use a C/pigment ratio of 60 , the daily consumption will be $0.85 \mu \mathrm{g}$ $\mathrm{C} \mathrm{d}^{-1}$, or, using a carbon constant of $4 \mu \mathrm{g} \mathrm{C}$ copepod $^{-1}$, $21 \%$ body $\mathrm{C} \mathrm{d}^{-1}$.

To recapitulate, the individual variance of gut contents of Acartia hudsonica in this work is less than that of other species of the same genus reported by other authors. This could be due to the persistence and homogeneity of the environmental conditions. The greatest synchrony was found in the bottom samples. Feeding activity was higher during the night, although a high proportion of night-time samples showed maxima and minima of individual variance. This nocturnal feeding was probably characterized by intense feeding burst of short duration. The random and discrete, step-by-step defecation process as compared with the semicontinuous pigment ingestion may contribute to the observed individual variance within nocturnal feeding pattern of the population.

Acknowledgments. This research was supported by a Fulbright grant to $\mathrm{V}$. Rodriguez and the research project of P. Donaghay. Partial support was provided by 2 CICYT projects, Mar-90-0339 and Mar-91-0813. We thank Ann Durbin for her invaluable assistance. We also thank C. A. Oviatt for use of her facilities at MERL, the staff of the Centro de Calculo of the University of Malaga and Mr David W. Schofield for his helpful suggestions in editing and translating the manuscript.

\section{LITERATURE CITED}

Baars, M. A., Helling, G. R. (1985). Methodological problems in the measurement of phytoplankton ingestion rate by gut fluorescence. Hydrobiol. Bull. 19: 81-88

Baars, M. A., Oosterhuis, S. S. (1984). Diurnal feeding rhythms in North Sea copepods measured by gut fluorescence, digestive enzyme activity and grazing on labelled food. Neth. J. Sea Res. 18: 97-119

Bautista, B., Rodriguez, V., Jimenez, F. (1988). Short-term feeding rates of Acartia grani in natural conditions: diurnal variation. J. Plankton Res. 10: $907-920$

Boyd, G. M., Smith, S. L., Cowles, T J. (1980). Grazing patterns of copepods in the upwelling system off Peru. Limnol. Oceanogr. 25: 583-596

Conover, R. J., Durvasula, R., Roy, S., Wang, R. (1986). Probable loss of chlorophyll-derived pigments during passage through the gut of zooplankton, and some of the consequences. Limnol. Oceanogr. 31: 878-887 
Dagg, M. J., Grill, D. W. (1980). Natural feeding rates of Centropages typicus females in the New York Bight. Limnol. Oceanogr. 25: 597-609

Dagg, M. J., Walser, W. E. Jr (1987). Ingestion, gut passage, and egestion by the copepod Neocalanus plumchrus in the laboratory and in the subartic Pacific Ocean. Limnol Oceanogr. 32: 178-188

Dagg, M. J., Wyman, K. D. (1983). Natural ingestion rates of the copepods Neocalanus plumchrus and $N$. cristatus calculated from gut contents. Mar. Ecol. Prog. Ser. 13 $37-46$

Dam, H. G., Peterson, W. T. (1988). The effect of temperature on the gut clearance rate constant of planktonic copepod J. exp. mar. Biol. Ecol. 49: 187-190

Daro, M. H. (1985). Feeding rhythms and vertical distribution of marine copepods. Bull. mar. Sci. 37: 487-497

Donaghay, P. L. (1988). Role of temporal scales of acclimation food quality and trophic dominance in controlling the evolution of copepod feeding behavior. Bull mar. Sci. 43 $469-485$

Durbin, A. G., Durbin, E. G., Wlodarczyk, E. (1990). Diel feeding behavior in the marine copepod Acartia tonsa in relation to food availability. Mar. Ecol. Prog. Ser. 68: 23-45

Hart, R. C. (1977). Feeding rhythmicity in a migratory copepod (Pseudocalanus hesses Mrazek). Freshwat. Biol. 7: 1-8

Head, E. J. H. (1992). Gut pigment accumulation and destruction by artic copepods in vitro and in situ. Mar. Biol. 112: $583-592$

Head, E. J. H., Harris, L. R. (1987). Copepod feeding patterns before and during a spring bloom in Bedford Basin, Nova Scotia. Mar. Ecol. Prog. Ser. 40: 221-230

Head, E. J. H., Harris, L. R., AbouDebs, C. (1985). Effect of daylength and food concentration on in situ diurnal feeding rhythms in Arctic copepods. Mar. Ecol. Prog. Ser. 24 $281-288$

Kiørboe, T., Moehlenberg, F., Nicolajsen, H. (1982). Ingestion rate and gut clearance in the planktonic copepod Centropages hamatus (Lilljeborg) in relation to food concentration and temperature. Ophelia 21: 181-194

Kiørboe, T., Møhlenberg, F., Riisgard, H. V. (1985). In situ feeding rates of planktonic copepods: a comparison of four methods. J. exp. mar. Biol. Ecol. 88: 67-81

Kiorboe, T., Tiselius, P. T. (1987). Gut clearance and pigment destruction in a herbivorous copepod, Acartia tonsa, and the determination of in situ grazing rates. J. Plankton Res. 9: $525-534$

Kleppel, G. S., Pieper, R. E., Trager, G. (1988). Variability in the gut contents of individual Acartia tonsa from waters off Southern California. Mar. Biol. 97: 185-190

Lambert, C. E., Oviatt, C. A. (1986). Manual of biological and geochemical techniques in coastal areas. MERL Series, Report No. 1, 2nd edn. Univ. of Rhode Island, Kingston

Lorenzen, C. J. (1966). A method for the continuous measurement of in vivo chlorophyll concentration. Deep Sea Res. 13: $223-227$

Lorenzen, C. J., Downs, J. N. (1986). The specific absorption coefficients of chlorophyllide $a$ and pheophorbide $a$ in

This article was submitted to the editor
$90 \%$ acetone, and comments on the fluorimetric determination of chlorophyll and pheopigments. Limnol. Oceanogr. 31: 449-452

Mackas, D., Bohrer, R. (1976). Fluorescence analysis of zooplankton gut contents and an investigation of diel feeding patterns. J. exp. Mar. Biol. Ecol. 25: 77-85

Mackas, D. L., Burns, K. E. (1986). Poststarvation feeding and swimming activity in Calanus pacificus and Metridia pacífica. Limnol Oceanogr. 31: 383-392

Madin, L. P., Cetta, C. M. (1984). The use of gut fluorescence to estimate grazing by oceanic salps. J. Plankton Res. 6 $475-492$

Mayzaud, O., Mayzaud, P., De LaBigue, C., Grohan, P. (1984). Diel changes in the particulate environment feeding activity and digestive enzyme concentration in neritic zooplankton. J. exp. mar. Biol. Ecol. 84: 15-35

Moebly, Ch. T. (1987). Time-series ingestion rate estimates on individual Calanus pacificus Brodsky: interactions with environmental and biological factors. J. exp. mar. Biol. Ecol. 144: 199-216

Morales, C. E., Bautista, B., Harris, R. P. (1990). Estimates of ingestion in copepod assemblages: gut fluorescence in relation to body size. In: Barnes, M., Gibson, R. N. (eds.) Trophic relationships in the marine environment. Aberdeen Univ. Press, Aberdeen, p. 565-577

Pagano, M., Saint-Jean, L. (1985). Premières données sur la nutrition d'Acartia clausi en Lagune Ebrie (Côte d'Ivoire) obtenues par des mesures de la fluorescence de broyats d'animaux. Hydrobiologie 121: 83-95

Penry, D. L., Jumars, P. A. (1986). Chemical reactor analysis and optimal digestion theory. BioScience 36: 310-315

Penry, D. L., Frost, B. W. (1990). Re-evaluation of the gutfullness (gut fluorescence) method for inferring ingestion rates of suspension-feeding copepods. Limnol. Oceanogr. 35: $1207-1214$

Peterson, W. T., Painting, S. J., Hutchings, L. (1990). Diel variations in gut pigment content, diel vertical migration and estimates of grazing impact for copepods in the Southern Benguela upwelling region in October 1987. J. Plankton Res. 12: 259-281

Rodriguez, V., Echevarría, F., Bautista, B., (1991). In situ die variation in gut pigment contents of Ceriodaphnia sp. in stratification and destratification periods. J. Plankton Res. 13: $187-196$

Roman, M. R., Ashton, K. A., Gauzens, A. L. (1988). Day/night differences in the grazing impact of marine copepods Hydrobiologia 167/168: 21-30

Simard, Y., Lacroix, G., Legendre, L. (1983). In situ twilight grazing rhythm during diel vertical migration of a scattering layer of Calanus finmarchicus. Limnol. Oceanogr. 30 $598-606$

Stearns, D. E. (1986). Copepod grazing behavior in simulated natural light and its relation to nocturnal feeding. Mar Ecol. Prog. Ser. 30: 65-76

Wang, R., Conover, R. J. (1986). Dynamics of gut pigment in the copepod Temora longicornis and the determination of in situ grazing rates. Limnol. Oceanogr. 31: 867-877

Manuscript first received: May 27, 1992

Revised version accepted: August 14, 1992 